\title{
Speciation of Phosphorus from Suspended Sediment Studied by Bulk and Micro-XANES
}

\author{
Qingxin Zhang ${ }^{1}$, Mackenzie Wieler ${ }^{1}$, David $\mathrm{O}^{\prime}$ Connell ${ }^{2, *}{ }^{\circledR}$, Laurence Gill ${ }^{2}{ }^{\mathbb{D}}$, Qunfeng Xiao ${ }^{3}$ \\ and Yongfeng $\mathrm{Hu}$ 1,3,* \\ 1 Department of Chemical and Biological Engineering, University of Saskatchewan, \\ Saskatoon, SK S7N 5A9, Canada; qiz393@mail.usask.ca (Q.Z.); mjw067@mail.usask.ca (M.W.) \\ 2 Department of Civil, Structural and Environmental Engineering, Trinity College Dublin, Dublin 2, Ireland; \\ laurence.gill@tcd.ie \\ 3 Canadian Light Source University of Saskatchewan, Saskatoon, SK S7N 2V3, Canada; \\ Qunfeng.xiao@lightsource.ca \\ * Correspondence: david.oconnell@tcd.ie (D.O.); Yongfeng.hu@lightsource.ca (Y.H.)
}

Received: 6 April 2020; Accepted: 16 August 2020; Published: 18 August 2020

\begin{abstract}
Mobilization, transformation, and bioavailability of fluvial suspended sediment-associated particulate phosphorus (PP) plays a key role in governing the surface water quality of agricultural catchment streams. Knowledge on the molecular P speciation of suspended sediment is valuable in understanding in-stream PP cycling processes. Such information enables the design of appropriate catchment management strategies in order to protect surface water quality and mitigate eutrophication. In this study, we investigated P speciation associated with fluvial suspended sediments from two geologically contrasting agricultural catchments. Sequential chemical P extractions revealed the operationally defined $P$ fractions for the fluvial suspended sediments, with Tintern Abbey (TA) dominated by redox-sensitive $\mathrm{P}\left(\mathrm{P}_{\mathrm{CBD}}\right), \mathrm{Al}$, and Fe oxyhydroxides $\mathrm{P}\left(\mathrm{P}_{\mathrm{NaOH}}\right)$ and organic $\mathrm{P}\left(\mathrm{P}_{\mathrm{Org}}\right)$ while Ballyboughal $(\mathrm{BB})$ primarily composed of acid soluble $\mathrm{P}\left(\mathrm{P}_{\text {Detr }}\right)$, redox-sensitive $\mathrm{P}\left(\mathrm{P}_{\mathrm{CBD}}\right)$, and loosely sorbed $\mathrm{P}\left(\mathrm{P}_{\mathrm{NH} 4 \mathrm{Cl}}\right)$. The dominant calcareous $(\mathrm{Ca})$ elemental characteristic of $\mathrm{BB}$ suspended sediment with some concurrent iron $(\mathrm{Fe})$ influences was confirmed by XRF which is consistent with the catchment soil types. Ca-P sedimentary compounds were not detected using bulk P K-edge XANES, and only P K-edge $\mu$-XANES could confirm their presence in BB sediment. Bulk P K-edge XANES is only capable of probing the average speciation and unable to resolve Ca-P as BB spectra is dominated by organic $\mathrm{P}$, which may suggest the underestimation of this $\mathrm{P}$ fraction by sequential chemical P extractions. Notably, $\mu$-XANES of Ca K-edge showed consistent results with P K-edge and soil geochemical characteristics of both catchments where Ca-P bonds were detected, together with calcite in BB, while in TA, Ca-P bonds were detected but mostly as organic complexed Ca. For the TA site, Fe-P is detected using bulk $\mathrm{P}$ K-edge, which corresponds with its soil geochemical characteristics and sequential chemical $\mathrm{P}$ extraction data. Overall, $\mathrm{P}$ concentrations were generally lower in TA, which led to difficulties in Fe-P compound detection using $\mu$-XANES of TA. Overall, our study showed that coupling sequential chemical $\mathrm{P}$ extractions with progressively more advanced spectroscopic techniques provided more detailed information on P speciation, which can play a role in mobilization, transformation, and bioavailability of fluvial sediment-associated P.
\end{abstract}

Keywords: phosphorus; sediment; chemical P extraction; microanalysis; $X$-ray absorption near-edge structure (XANES) spectroscopy

\section{Introduction}

There has been increasing awareness of the importance of fluvial suspended sediments in the transport of nutrients from agricultural catchments, which can degrade water quality and cause 
eutrophication [1]. A significant proportion of total phosphorus (TP) loads in agricultural streams is transported as particulate phosphorus (PP) or within the fluvial suspended sediment PP [2,3]. Suspended sediment-associated $\mathrm{P}$ is deposited on the riverbed channel or on floodplains and its subsequent remobilization must therefore have an important impact on the transport, delivery pathway and fate of P species within agricultural catchments. Deposition on the river channel bed or floodplains can result in short- or long-term P storage. Similarly, remobilization of riverbed sediments coupled with bank erosion can reintroduce $\mathrm{P}$ to the river channel. Hence, information on P fluxes, storage, mobilization, and bioavailability within agricultural streams is required for appropriate catchment scale management policies. While research has addressed the increasing recognition of the importance of sediment PP within freshwater systems, relatively little attention has been given to $\mathrm{P}$ in suspended and streambed sediments within agricultural catchments, with the majority of research focusing on $P$ in soils and lentic sediments (lakes and reservoirs, etc.). Relatively few studies have specifically characterized and quantified P species within streambed sediments [4,5], and fewer still in fluvial suspended sediments [6]. Many studies have shown that in catchments with diffuse sources, episodic flooding events and surface water runoff control stream bed and suspended solid composition and fluxes over time [7-9]. In addition to $P$ and organic matter, the concentration and form of metal complexes and their link to microbial mineralization processes are likely impacted by fluvial and stream bed sediments. For example, it has been shown that organic matter remineralization predominates P cycling in Chesapeake Bay sediments $[10,11]$ and the formation of phosphate-Fe(III)-humic complexes significantly impact $\mathrm{P}$ cycling and sedimentary $\mathrm{Fe}(\mathrm{III})$ stabilization in organic matter Fe-rich lake sediments, which is rarely recognized $[12,13]$. Hence, the molecular forms of $\mathrm{P}$ and their association to metal species of fluvial and stream bed sediments are important for understanding P transformation, mobility, and the potential impact on surface water eutrophication.

Sequential chemical extractions (SCEs) have been widely used to assess and quantify P species with different binding mechanisms and bioavailability. The basis of such fractionation analyses is in the differential reactivity of solid substrates to various chemical extractants [14]. Hence, such chemical extraction methods provide only operationally defined $\mathrm{P}$ pools and do not directly determine $\mathrm{P}$ speciation [15]. Notwithstanding their widespread application, there are various limitations associated with many sequential chemical $P$ extraction schemes, including: (1) the specificity of extracting agents for sedimentary chemical $\mathrm{P}$ forms is relative; (2) transformation processes during the extractions between fractions (i.e., $\mathrm{P}$ sorption on calcite from calcareous sediments may be extracted in the Fe-oxide CBD extractant step). For example, during extraction of organic matter-rich sediments using the original Psenner method, $\mathrm{Al}$ and Fe associated with humic acid complexes are often misappropriated [16-18]. In the original method, Fe-bound P is extracted using bicarbonate-buffered dithionite followed by extraction of Al-oxide-bound $\mathrm{P}$ using $\mathrm{NaOH}$. Concurrently, within this $\mathrm{NaOH}$ treatment, significant organic matter-bound $\mathrm{P}$ is extracted. Hence an additional step involving the acidification of the $\mathrm{NaOH}$ treated sediments $(\mathrm{pH} \sim 1)$ precipitated humic acid (HA) associated Fe and $\mathrm{Al}$ resulting in a clear supernatant with precipitate containing up to $30 \%$ of the total sediment $\mathrm{P}$ [17]. Similarly, another SCE [19] for sedimentary P was modified for organic-rich sediments with insertion of an additional extraction step $\left(\mathrm{Na}_{2} \mathrm{CO}_{3}\right)$ prior to the Fe-bound $\mathrm{P}$ focused on bicarbonate-buffered dithionite step in order to extract Fe and Al humic complexes [12,20]. Despite such limitations, SCEs are still useful to get initial estimates of sedimentary chemical P pools. However, more recently, synchrotron-based P K-edge X-ray absorption near-edge structure (XANES) spectroscopy [21,22] and solution ${ }^{31} \mathrm{P}$ nuclear magnetic resonance (NMR) $[23,24]$ have been applied to directly probe and distinguish different $P$ species in terms of the inorganic form (XANES) and organic P species (NMR). More importantly, the feasibility and advantages of the combined use of these techniques in soil and sediment speciation have been demonstrated [11,12,25-27]. While such advanced spectroscopic techniques are capable of providing bulk speciation information for soil and sediment $\mathrm{P}$, microclusters of concentrated P may be overlooked. Such P speciation information on microclusters of concentrated $\mathrm{P}$ is important, particularly for heterogeneous samples where correlations between $\mathrm{P}$ and metal 
species are necessary to understand the transfer and transformation of $\mathrm{P}$ in dynamic systems [28,29]. In this study, our objectives were to: (i) couple chemical P fractionation with the bulk and P K-edge micro $(\mu)$-XANES to show the tiered approach in studying P compositional dynamics in suspended fluvial sediments from geologically contrasting agricultural and; (ii) apply bulk and P K-edge $\mu$-XANES to give progressively more accurate and detailed compositional information compared to chemical $\mathrm{P}$ fractionations; (iii) show how bulk and P K-edge $\mu$-XANES can identify P species in detail and the correlation between $\mathrm{P}, \mathrm{Ca}$, and Fe elements from suspended solids from two geologically contrasting agricultural catchments in Ireland.

\section{Materials and Methods}

Suspended sediment samples were collected from two agricultural catchments located in the east and southeast of Ireland, namely, Ballyboughal (BB) and Tintern Abbey (TA), as shown in Figure 1. Both catchment streams are medium- to high-level eutrophic according to the 2015-2017 water quality map released by the Irish Environment Protection Agency [30], which makes them suitable locations to study the influences of agricultural catchment sediments to fluvial waters. The BB site has an area of $23 \mathrm{~km}^{2}$, with soils primarily composed of river alluvium, fine loamy drift with limestones, and siliceous stones. TA has an area of $10 \mathrm{~km}^{2}$, with soils composed of primary river alluvium and fine loamy drift with siliceous stones.

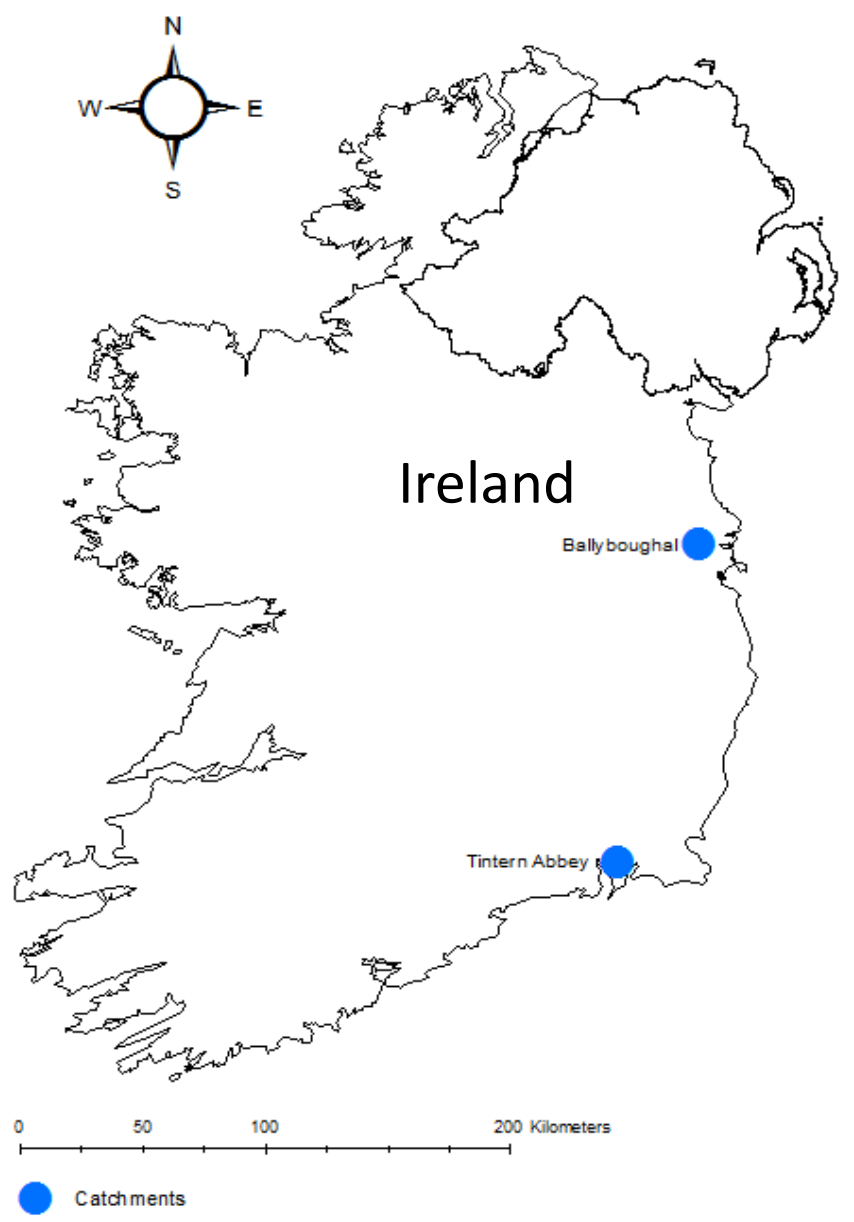

Figure 1. Location of the Ballyboughal (BB) and Tintern Abbey (TA) catchments in Ireland.

Fluvial sediment was gathered using time-integrated sediment traps, which were deployed to collect in-stream suspended solids over a 10-week period. One time period of samples was collected for this study, and taking into account the significant period of time (10 weeks) the traps were left in place, it is reasonable to consider the samples are representative of the catchment areas. Such sediment traps 
are known as Philips samplers [31], and their ability to collect suspended soils is based on slowing down the water velocity, resulting in sediment accumulation within the sediment trap tube. These samplers were installed horizontally in the middle of the channel and installed securely at approximately $60 \%$ of the average water depth using steel uprights and plastic cable ties to steel rebar embedded deep into the river channel [28]. The sediment traps were carefully removed from streams and emptied into clean $10 \mathrm{~L}$ containers which are kept as near as possible to the stream temperature while being transported back to the laboratory. The sediments were stored in a refrigerator for a few hours and processed by wet sieving the fluvial sediment through $63 \mu \mathrm{m}$ steel stainless sieves, then centrifuged, and the supernatant decanted. The sediments were then freeze-dried for further analyses.

The sediment samples were sequentially extracted using a modified chemical extraction procedure [16,32], as shown in the flow diagram (Figure 2). Briefly, $1 \mathrm{M} \mathrm{NH}_{4} \mathrm{Cl}$ was used to extract $\mathrm{P}$ adsorbed loosely to surfaces $\left(\mathrm{P}_{\mathrm{NH} 4 \mathrm{Cl}}\right)$; bicarbonate-dithionate $(\mathrm{BD})$ extraction represents redox-sensitive $\mathrm{P}$ that is mainly bound to oxidized Fe and $\mathrm{Mn}$ compounds $\left(\mathrm{P}_{\mathrm{CBD}}\right) ; 0.1 \mathrm{M} \mathrm{NaOH}$ was used to extract inorganic $\mathrm{P}$ compounds, such as $\mathrm{Al}$ and Fe oxyhydroxides $\left(\mathrm{P}_{\mathrm{NaOH}}\right)$ and poly- $\mathrm{P}$, $\mathrm{P}$ in detritus or complexes $\left(\mathrm{P}_{\mathrm{NRP}}\right)$; humic $\mathrm{P}$ complexes $\left(\mathrm{P}_{\text {hum }}\right)$, acid-soluble $\mathrm{P}$ mainly bound to $\mathrm{Ca}$ (especially apatite), and $\mathrm{Mg}$ were differentiated using $0.5 \mathrm{M} \mathrm{HCl}\left(\mathrm{P}_{\text {Detr }}\right)$; and, lastly, the residual $\mathrm{P}$ $\left(\mathrm{P}_{\text {Res }}\right)$ represents refractory organic $\mathrm{P}$ and non-extractable mineral $\mathrm{P}$ extracted using $1 \mathrm{M} \mathrm{HCl}$ at $120^{\circ} \mathrm{C}$. Phosphorus assumed to be associated with humic matter was precipitated by adding $2 \mathrm{M} \mathrm{H}_{2} \mathrm{SO}_{4}$ to a subsample of the $\mathrm{NaOH}$ extract [17]. Organic $\mathrm{P}$ (Figure 2) is calculated as the difference in TP between the first $\mathrm{NaOH}$ step and the second digested $\mathrm{NaOH}$ step [18].

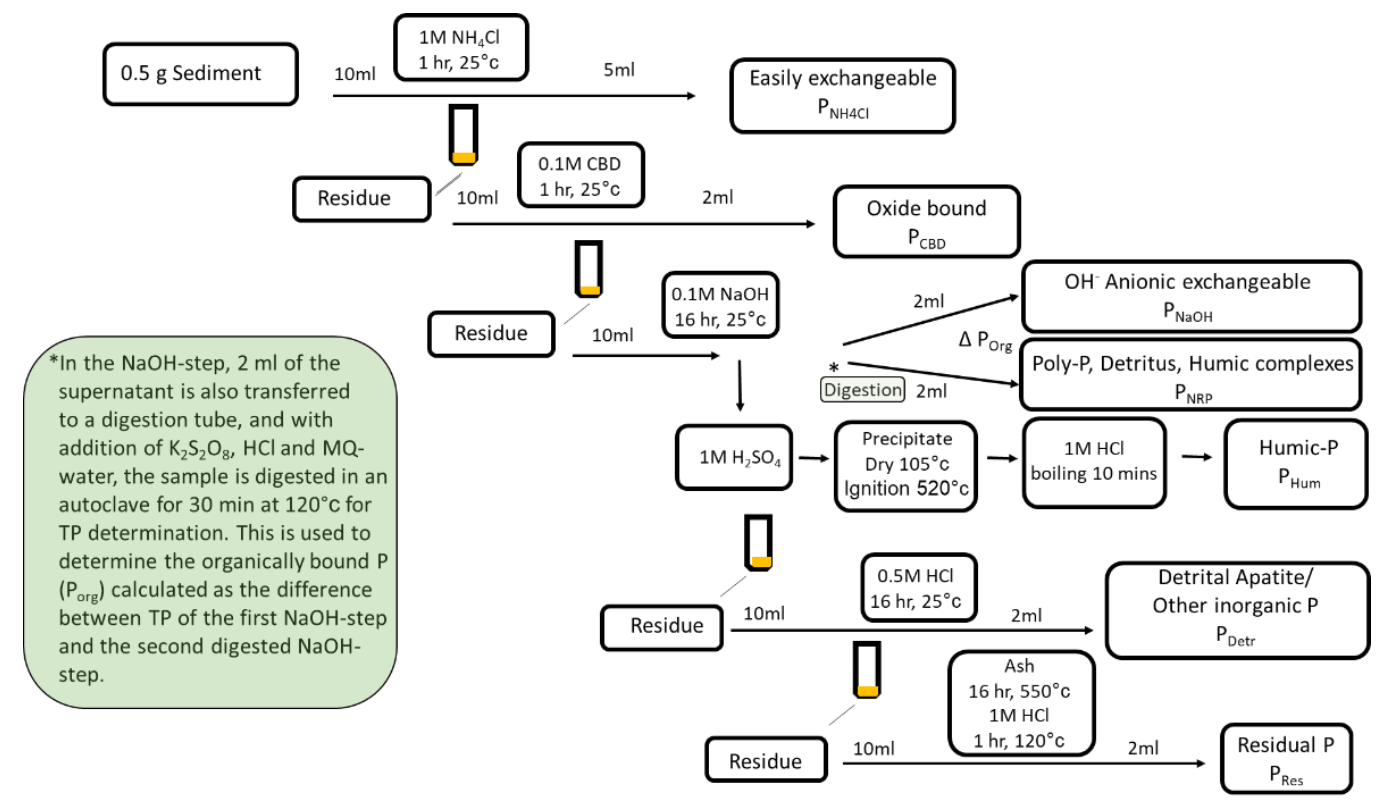

Figure 2. Modified Psenner sequential chemical P extraction procedure flow diagram [16,32].

The bulk and $\mu$-XANES at $\mathrm{P}, \mathrm{Ca}$, and Fe K-edges were recorded using the Soft X-ray Microcharacterization Beamline (SXRMB) beamline at the Canadian Light Source. At SXRMB, a DCM monochromator using Si (111) crystals is used to cover an energy range of 2-10 keV. At the bulk station, the powder samples were mounted on the double-sided carbon tape and loaded into the vacuum chamber. The bulk spectra were recorded using a 7-element Si drift detector for sediment samples with low $\mathrm{P}$ concentration, and in TEY mode for reference samples. A pair of KB mirrors was used to focus the beam to a spot size of $10 \mu \mathrm{m} \times 10 \mu \mathrm{m}$ with $10^{9}$ photons/100mA/s flux [33]. A high-resolution and large area CCD camera is equipped to obtain the optical image of sample. A 4-element Si drift detector is used for $\mu$-XANES analysis. A thin layer of sediment was spread on the carbon tape, and a large area of sample $\left(3 \times 3 \mathrm{~mm}^{2}\right)$ was first mapped with coarse resolution. Fine-resolution $\mu$-XRF maps were acquired by selecting areas based on the elemental distribution and correlation. P, Ca, and Fe $\mu$-XANES 
were acquired for selected hotspots. A photon energy of $7200 \mathrm{eV}$ was used to record the XRF maps so that the distribution of $\mathrm{P}$ and other relevant elements can be tracked.

\section{Results and Discussion}

\subsection{Total P and P Fractionation in Suspended Sediments}

In this study, the overall median TP concentrations in the fluvial suspended sediments from the sum of all sedimentary P fractions at the Ballyboughal (BB) outflow was $3.4 \mathrm{mg} \cdot \mathrm{g}^{-1}$, and for the Tintern Abbey (TA) outflow, it was $0.9 \mathrm{mg} \cdot \mathrm{g}^{-1}$ (Figure 3a). Such TP concentrations are comparable with previous studies on fluvial suspended and streambed sediments [5]. There is a relatively high TP concentration observed for the BB fluvial suspended sediment, likely due to additional sedimentary $\mathrm{P}$ contributions from domestic septic tanks and village wastewater treatment plant (WWTP) outflows [34] as the catchment is a relatively highly populated agricultural catchment in north county Dublin, Ireland.

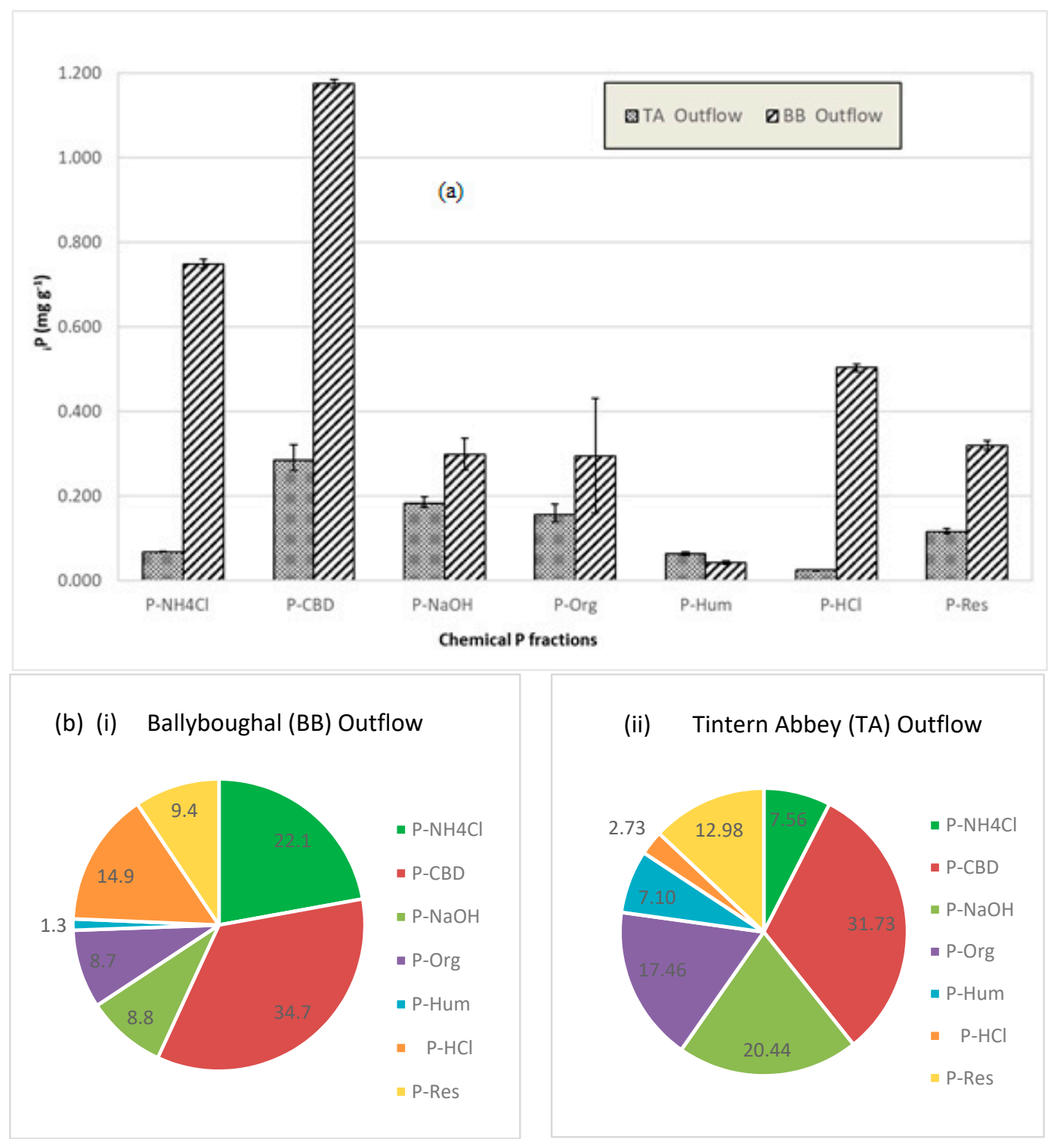

Figure 3. (a) Sequential chemical $P$ fraction pools including total $P\left(\mathrm{mg} \mathrm{g}^{-1} \mathrm{DW}\right)$ for (a) Ballyboughal outflow (BB) and (b) Tintern Abbey outflow (TA); (b) sequential chemical P fractionations in relative percent (\%) for (i) Ballyboughal (BB) outflow and (ii) Tintern Abbey (TA) outflow. 
Within the $\mathrm{BB}$ suspended sediments, the most dominant $\mathrm{P}$ fractions included $\mathrm{P}_{\mathrm{CBD}}, \mathrm{P}_{\mathrm{Org}}$, and $\mathrm{P}_{\mathrm{NH} 4 \mathrm{Cl}}$ with concentrations of $1.18,0.3$, and $0.75 \mathrm{mg} \cdot \mathrm{g}^{-1}$, respectively. By contrast, the most prevalent $\mathrm{P}$ fractions in the TA sediments were the $\mathrm{P}_{\mathrm{CBD}}, \mathrm{P}_{\mathrm{NaOH}}$, and $\mathrm{P}_{\mathrm{Org}}$ with concentrations of 0.29 , 0.18 , and $0.16 \mathrm{mg} \cdot \mathrm{g}^{-1}$ (Figure $3 \mathrm{a}$ ). Figure $3 \mathrm{~b}$ presents the relative proportional percentage chemical $\mathrm{P}$ fractionation results of representative fluvial suspended sediments from (i) BB and (ii) TA sites. The sequential chemical P fractionations separated the fluvial sediment TP into pools with diverse bioavailability. The distribution of $\mathrm{P}$ fractions differs in the suspended solids of the two geologically contrasting agricultural catchments. Loosely sorbed $\left(\mathrm{P}_{\mathrm{NH} 4 \mathrm{Cl}}\right)$ was elevated at $22 \%$ in $\mathrm{BB}$ while there was a lower percentage at $7.5 \%$ in TA. The BB agricultural catchment is typical of many Irish agricultural catchments in that additional $\mathrm{P}$ contributions, including $\mathrm{P}_{\mathrm{NH} 4 \mathrm{Cl}}$, may come from domestic septic systems or from village WWTP outflows [34]. The relative $\mathrm{P}_{\mathrm{CBD}}$ fraction which constitutes $\mathrm{P}$ bound to reducible species of Fe and Mn was almost the same in the suspended solids of both catchments being slightly elevated at the TA outflow at $\sim 32 \%$ in comparison to $\sim 35 \%$ at the BB outflow. Within the BB suspended solids, there is a relatively elevated percentage composition of $\mathrm{P}_{\text {Org }}, \mathrm{P}_{\text {Detr }}$ ( $\mathrm{P}$ bound to $\mathrm{Ca}$ and $\mathrm{Mg}$ ), and $\mathrm{P}_{\text {Res }}$ at $\sim 9 \%$ for all three. The relative percentage composition of organic $\mathrm{P}$ for TA is $\sim 17 \%$. A previous study on fluvial suspended solids from the mixed land-use Bras d'Henri River watershed in Quebec City, Canada, reported $P_{\text {Org }}$ comprising up to $20 \%$ of TP using sequential chemical $\mathrm{P}$ fractionations, which was an order of magnitude greater than streambed sediments [5]. Previous studies have shown that mineralization of organic $\mathrm{P}\left(\mathrm{P}_{\mathrm{Org}}\right)$ to inorganic $\mathrm{P}\left({ }_{\mathrm{i}} \mathrm{P}\right)$ through enzymatic hydrolysis has a direct effect on $\mathrm{P}$ bioavailability in freshwater systems [35,36]. In addition, the TA outflow suspended sediment contains relatively elevated $\mathrm{P}_{\mathrm{Hum}}$ and $\mathrm{P}_{\mathrm{NaOH}}$ at $\sim 7 \%$ and $\sim 20.5 \%$, which may be associated with the higher $\mathrm{Fe}$ and $\mathrm{Al}$ concentrations reflected in the catchment soils [34]. The $\mathrm{P}_{\text {Hum }}$ fraction may include $\mathrm{Fe}(\mathrm{III})$-bearing colloids or organic matter-Fe(III)-P ternary complexes which can play an important role in $\mathrm{P}$ transport $[8,12,17]$. BB sediment samples clearly showed a higher relative fraction of $\mathrm{P}$ extracted by $\mathrm{HCl}\left(\mathrm{P}_{\text {Detr }}\right) \sim 15 \%$, indicating the presence of relatively elevated Ca-bound $\mathrm{P}$, in agreement with the calcareous soils of the catchment [37]. The BB catchment does contain some areas rich in sandstone with elevated $\mathrm{Fe}$, which may influence the relatively elevated percent composition redox-sensitive $\mathrm{P}\left(\mathrm{P}_{\mathrm{CBD}}\right)$ fraction. The relative percentage of redox-sensitive $\mathrm{P}$ $\left(\mathrm{P}_{\mathrm{CBD}}\right)$ and $\mathrm{NaOH}$-extracted $\mathrm{P}\left(\mathrm{P}_{\mathrm{NaOH}}\right)$ are both elevated in the TA sediment, consistent with the Fe-rich composition of the local mineralogy in the TA catchment [34]. The origin of such redox-sensitive $\mathrm{P}\left(\mathrm{P}_{\mathrm{CBD}}\right)$ and $\mathrm{Al}$ and $\mathrm{Fe}$ oxyhydroxide $\mathrm{P}\left(\mathrm{P}_{\mathrm{NaOH}}\right)$ fractions is associated with redox fluctuations impacting $\mathrm{Fe}(\mathrm{III})$-oxides in hyporheic and riparian environments [38]. Organic matter degradation creates reducing anoxic conditions in such environments, particularly in summer, which can lead to reductive dissolution of $\mathrm{Fe}(\mathrm{III})$-oxides to release Fe(II) and sorbed P [38,39].

\subsection{Compositional Validation of Suspended Sediment Using X-Ray Fluorescence (XRF) and X-ray Absorption} Near-Edge Structure (XANES)

The elemental compositions of these sediments as detected by X-ray fluorescence (XRF) (Figure 4) also show that the BB sediment has a much higher Ca concentration, while the TA sediment has a relatively higher Fe content. This is in general agreement with results from sequential chemical $P$ fractionations which indicated more Ca-associated $\mathrm{P}$ within $\mathrm{BB}$ sediments and more Fe and/or redox associated P with TA sediments (Section 3.1; Figure 3). Previous studies have used synchrotron XRF coupled with operationally defined chemical $\mathrm{P}$ fractionation results to establish the dominant elements governing sediment composition [40-44]. 


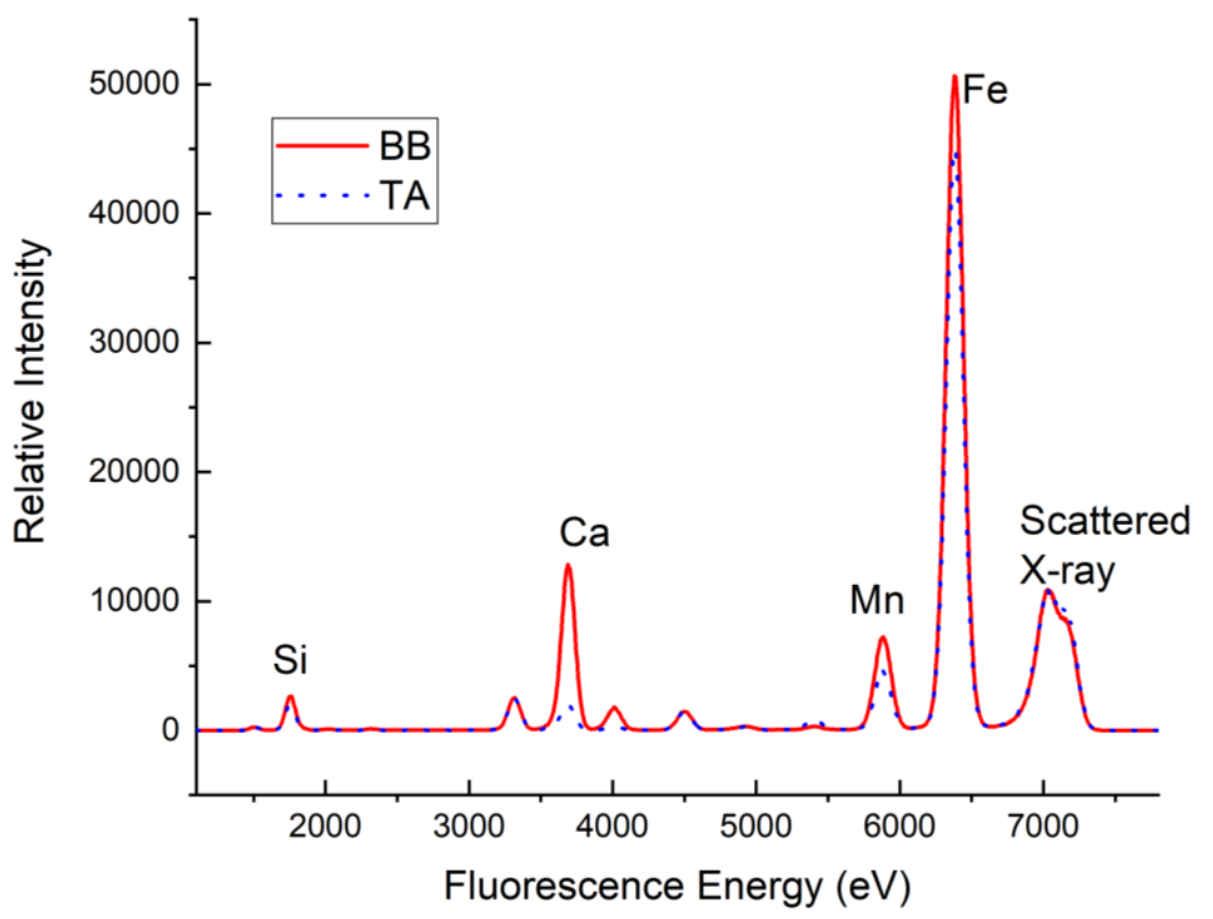

Figure 4. X-ray fluorescence spectra of bulk TA and BB sediments. The intensity was calibrated relative to the scattered X-ray (to an intensity of 10000 at $7000 \mathrm{eV}$ ), so that the comparison of elemental intensities is possible. The incident photon energy is $7200 \mathrm{eV}$.

Figure 5 shows the P K-edge spectra of (a) bulk TA and BB sediments and in comparison to (b) the spectra of selected $\mathrm{P}$ reference compounds. The Fe phosphate-related compounds have a unique pre-edge peak, as indicated by the arrow in the spectrum of $\mathrm{FePO}_{4} \cdot 2 \mathrm{H}_{2} \mathrm{O}$ shown in Figure $5 \mathrm{~b}$, while the Ca phosphate compounds, such as apatite, have several distinct shoulders in their P K-edge XANES [21,25]. P K-edge spectra of bulk sediment samples were dominated by featureless post-edge peak, similar to that of phytic acid [45]. This indicates the relatively significant presence of organic $P$ $\left(\mathrm{P}_{\mathrm{Org}}\right)$ in these samples, which may suggest the $\mathrm{P}_{\mathrm{Org}}$ fraction of the chemical $\mathrm{P}$ fractionation results underestimate the significance of this P pool (Figure 3). The pre-edge peak, as indicated by the arrow, is clearly resolved in the spectrum of the TA sediment (Figure 5a), suggesting the presence of Fe-P in the bulk of TA sediment. This is in agreement with the chemical extraction and bulk XRF results (Figures 3 and 4). However, for Ca-rich BB sediment, no Ca-P related resonances are observed in the spectrum of BB sediment.
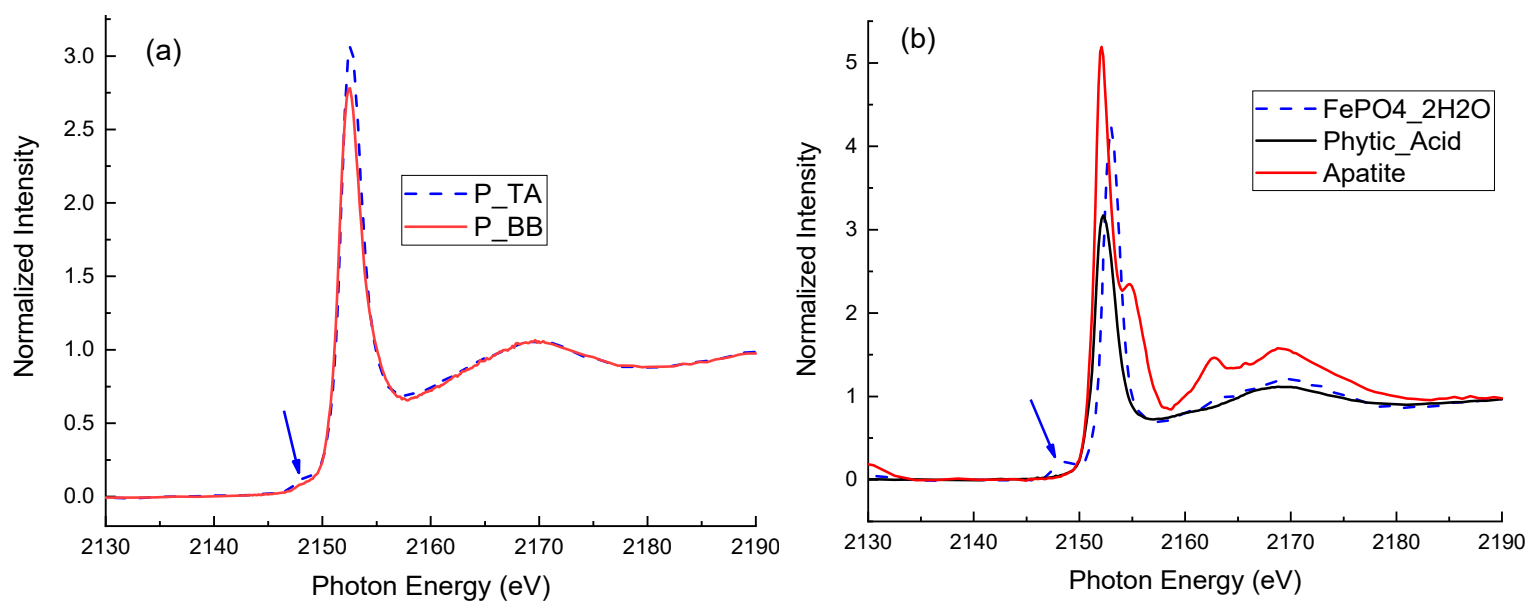

Figure 5. P K-edge XANES spectra of (a) bulk TA and BB sediments and (b) reference compounds. 
This lack of Ca-P in the bulk spectrum of BB sediment implies the dominance of organic $\mathrm{P}$ and the inhomogeneous distribution of Ca-P in the BB sediment, which could be revealed by the microanalysis of these sediments. Chemical $\mathrm{P}$ fractionation results indicated a significant Ca-P pool normally associated with a recalcitrant mineral such as apatite. The tricolor $\mu$-XAF maps of two sediments are shown in Figure 6. In this work, we chose to focus on the correlations between $\mathrm{P}, \mathrm{Fe}$, and $\mathrm{Ca}$, as $\mathrm{Fe}$ oxides have been shown to complex with organic matter in sediments, thus impacting P mobility and surface water eutrophication [10-12]. The important role of Ca-P species in sediment weathering, $\mathrm{P}$ transformation in alkaline soil, and biogeochemical $\mathrm{P}$ cycling has been demonstrated by microscale XRF mapping, together with ${ }^{31} \mathrm{P}$ NMR and chemical extraction $[27,42,43]$. In Figure 6, elemental correlation maps or hotspot maps down to the micron scale are shown for P (blue), $\mathrm{Ca}$ (green), and $\mathrm{Fe}$ (red). These are elemental correlation maps with comparison of relative elemental concentration within a specified hotspot/area and not absolute concentrations. Where necessary, the hotspot can be identified down to 10 microns for $\mu$-XANES. It is obvious that there are more Ca-rich hotspot correlations with $\mathrm{P}$ in the BB catchment. The BB sample also has very few and weak Fe spots, but there are identifiable Ca- and P-correlated spots (such as A). The TA sediment is generally Fe-rich, with only one Ca-rich hotspot. This is consistent with the XRF analysis and the mineralogy of these sites. A few hotspots ( $A, B, C$ as P-rich, Fe-rich, and Ca-rich for BB sediment and $D, E$ as Fe-rich and Ca-rich for TA sediment, respectively) are selected for $\mathrm{P}, \mathrm{Ca}$, and Fe $\mu$-XANES.
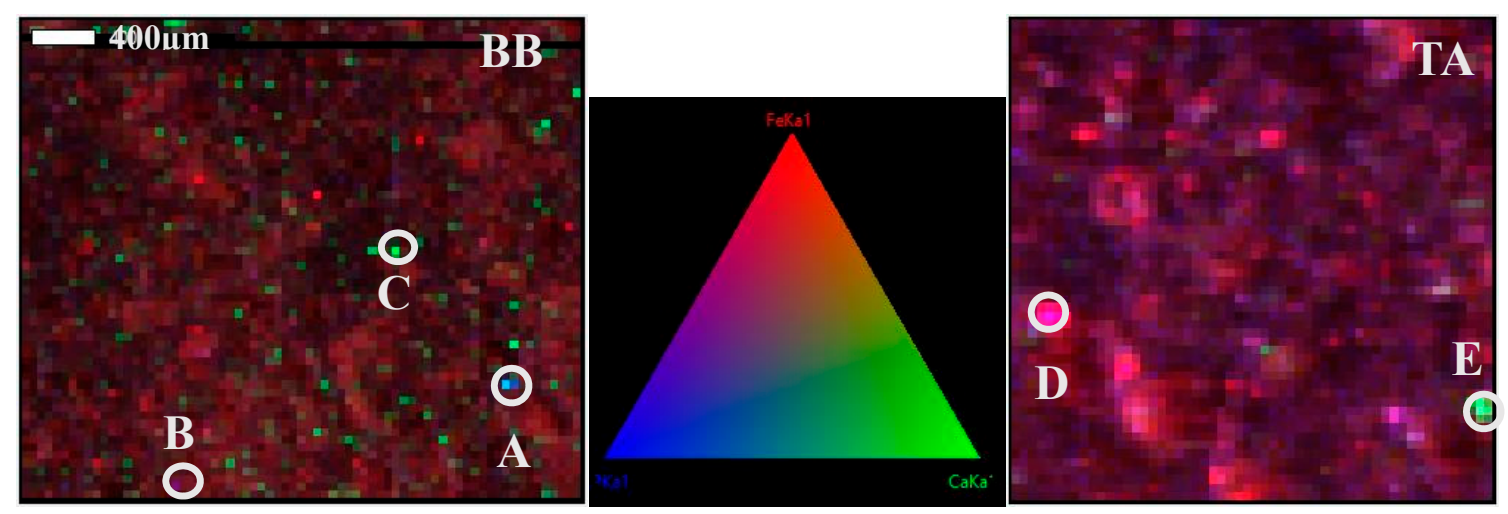

Figure 6. Elemental mapping for P (blue), Ca (green) and Fe (red) of BB and TA sediments with selected spots.

Figure 7a,b present the P K-edge $\mu$-XANES of hotspots or region of interests (ROI) for BB and TA sediments. The $\mathrm{P}$ spectra for TA sediments $(D$ and $E)$ were quite noisy and without distinct features associated with inorganic $\mathrm{P}$ (Figure $7 \mathrm{~b}$ ), confirming its weak and significant organic $\mathrm{P}$ (Figure 3). The $\mu$-XRF map of the TA sample revealed that ROI $D$ had high Fe and $\mathrm{P}$ correlation (Figure 6); unfortunately, Fe-P could not be resolved in its $\mu$-XANES (Figure 7b), likely due to its low $\mathrm{P}$ concentration and interference from the high Si content (Figure 4). For the $\mathrm{Ca}$ - and P-rich hotspots of BB sediment, the post-edge resonances were clearly resolved (Figure $7 \mathrm{a}$, spots $A$ and $C$ ), indicating the high $\mathrm{Ca}-\mathrm{P}$ in the BB site. This is in agreement with the chemical extraction result, demonstrating the advantage of the $\mu$-XANES, as no Ca-P was detected in the bulk P K-edge (Figure 5a). On the contrary, no Ca-P is detected in the $\mu$-XANES of spot $\mathrm{B}$, as it shows high Fe and $\mathrm{P}$ correlation (Figure 6 ). There might be a hint of the pre-edge peak in the $\mathrm{P}$ K-edge of spot $\mathrm{B}$, implying the presence of Fe-P. Results of Ca K-edge $\mu$-XANES (Figure 7c) are also in agreement with the P K-edge $\mu$-XANES, as Ca in spot A matches well with that of apatite, spots $B$ and $C$ being mostly calcite, and spots $D$ and $E$ being mostly organic Ca [25]. The Fe K-edge $\mu$-XANES of all spots (Figure 7d) are similar to each other and to those of bulk samples, as they are dominated by Fe hydroxyl oxide species [11,45]. No Fe-P can be resolved in the Fe K-edge $\mu$-XANES due to its relatively low concentration. 

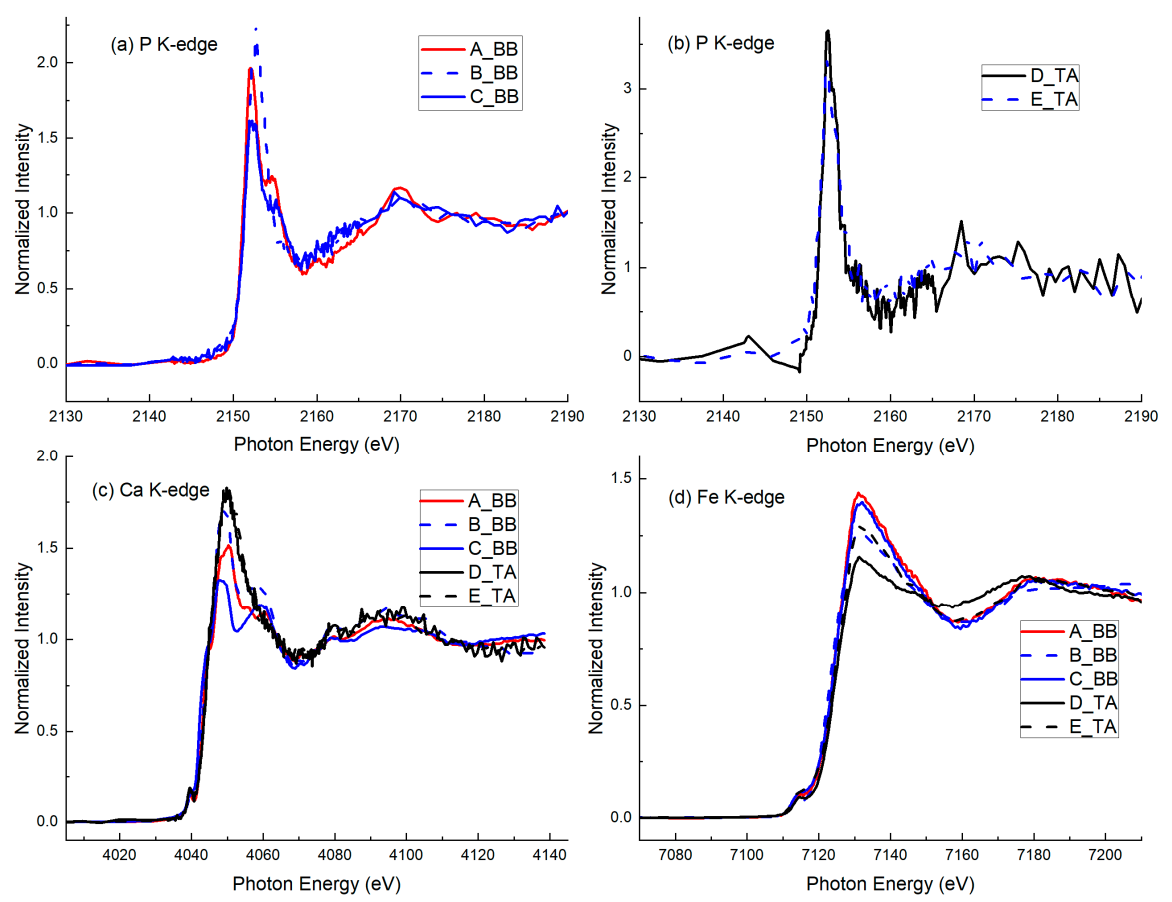

Figure 7. $\mu$-XANES of selected spots identified in Figure 5: (a,b) P K-edge; (c) Ca K-edge and (d) Fe K-edge.

\section{Conclusions}

The chemical speciation of fluvial suspended sediment-associated PP from two geologically contrasting agricultural sites was studied by chemical extraction and bulk and $\mu$-XANES. It was demonstrated that the microanalysis of P K-edge, combined with the $\mu$-XANES of Ca and Fe K-edge, is critical to achieving a detailed characterization of the PP species. The limestone nature of BB was confirmed by XRF, which is consistent with the soil type at the BB site. The chemical confirmation of Ca-P-containing compounds in BB sediments was revealed only by P K-edge $\mu$-XANES and not by its bulk spectrum, as the bulk XANES was only capable of probing the average speciation. Using bulk $\mathrm{P}$ K-edge XANES, it was difficult to resolve Ca-P peaks as the BB spectra is dominated by organic $\mathrm{P}$. For the TA location, Fe-P containing compounds were detected by P K-edge XANES, which correlates with its soil geochemical characteristics and the sequential chemical P extraction data. Notably, the $\mathrm{P}$ concentration is generally lower in TA, which makes it difficult to detect Fe-P in the $\mu$-XANES of TA. $\mu$-XANES of Ca K-edge was consistent with the P K-edge and the geochemical characteristics of the study sites (i.e., both Ca-P associated with apatite and calcite detected in BB; TA has mostly organic $\mathrm{Ca}$ ). A significant amount of organic $\mathrm{P}$ was detected in these sediments using P K-edge XANES which suggested the sequential chemical $P$ extractions may have underestimated its importance. Overall, our study provided additional, detailed information on the $\mathrm{P}$ speciation associated with fluvial sediments by coupling sequential chemical $P$ extractions with progressively more advanced spectroscopy, including XRF, bulk-XANES, and $\mu$-XANES of multiple elements. This additional knowledge contributes to our understanding of the geochemical processes governing P mobilization, bioavailability, and transformation to potentially inform improved agricultural catchment management policies to protect the water quality of associated rivers and streams.

Author Contributions: D.O.; L.G. and Y.H. designed the study. Q.Z.; M.W.; D.O. collected the samples and performed most data measurement and analyses. Q.X. and Y.H. collected the XRF and XANES data. Y.H. and D.O. did most of the writing with inputs from all. All authors have read and agreed to the published version of the manuscript. 
Funding: This work has been funded by the Natural Sciences and Engineering Research Council of Canada (NSERC) in collaboration with the Irish EPA (EPA), the Irish Department of Agriculture, Food and the Marine (DAFM) and WaterWorks Joint Call (WTWPJ 506072-2016).

Acknowledgments: We would like to acknowledge the support of numerous staff and scientists at the Canadian Light Source, which is supported by Canadian Foundation for Innovation, NSERC and the University of Saskatchewan. In addition, we acknowledge the support from the technical staff of the Environmental Engineering Research laboratory in Trinity College Dublin, Ireland.

Conflicts of Interest: The authors declare no conflict of interest. The funders had no role in the design of the study; in the collection, analyses, or interpretation of data; in the writing of the manuscript, or in the decision to publish the results.

\section{References}

1. Pulley, S.; Foster, I.D.L.; Antunes, A.P.M. The dynamics of sediment-associated contaminants over a transition from drought to multiple flood events in a lowland UK catchment. Hydrol. Process. 2016, 30, 704-719. [CrossRef]

2. Ballantine, D.J.; Waling, D.E.; Collins, A.L.; Leeks, G.J.L. The phosphorus content of fluvial suspended sediment in three lowland groundwater-dominated catchments. J. Hydrol. 2008, 357, 140-151. [CrossRef]

3. Sharpley, A.N.; Bergstrom, L.; Aronsson, H.; Bechmann, M.; Bolster, C.H.; Borling, K.; Djodjic, F.; Jarvie, H.P.; Schoumans, O.F.; Stamm, C.; et al. Future agriculture with minimized phosphorus losses to waters: Research needs and direction. AMBIO 2015, 44, S163-S179. [CrossRef] [PubMed]

4. Zhang, W.; Shan, B.; Zhang, H.; Tang, W. Assessment of preparation methods for organic phosphorus analysis in phosphorus-polluted Fe/Al-rich Haihe river sediments using solution ${ }^{31}$ P-NMR. PLoS ONE 2013, 8, e76525. [CrossRef]

5. Su, J.; van Bochove, E.; Auclair, J.-C.; Theriault, G.; Denault, J.T.; Bosse, C.; Li, X.; Hu, C. Phosphorus algal availability and release potential in suspended and streambed sediments in relation to sediment and catchment characteristics. Agricul. Ecosyst. Environ. 2014, 188, 169-179. [CrossRef]

6. Stutter, M.I.; Langan, S.J.; Lumsdon, D.G.; Clark, L.M. Multi-element signatures of stream sediments and sources under moderate to low flow conditions. Appl. Geochem. 2009, 24, 800-809. [CrossRef]

7. Lamba, J.; Karthikeyan, K.G.; Thompson, A.M. Using radiometric fingerprinting and phosphorus to elucidate sediment transport dynamics in an agricultural watershed. Hydrol. Process. 2015, 29, 2681-2693. [CrossRef]

8. Bol, R.; Gruau, G.; Mellander, P.-E.; Dupas, R.; Bechmann, M.; Skarbovik, E.; Bieroza, M.; Djodjic, F.; Glendell, M.; Jordan, P.; et al. Challenges of reducing phosphorus based water eutrophication in the agricultural landscapes of Northwest Europe. Front. Mar. Sci. 2020, 32, 276. [CrossRef]

9. Gaspar, L.; Lizaga, I.; Blake, W.H.; Latorre, B.; Quijano, L.; Navas, A. Fingerprinting changes in source contribution for evaluating soil response during an exceptional rainfall in Spanish pre-pyrenees. J. Environ. Manag. 2019, 240, 136-148. [CrossRef]

10. Joshi, S.R.; Kukkadapu, R.K.; Burdige, D.J.; Bowden, M.E.; Sparks, D.L.; Jaisi, D.P. Organic matter remineralization predominates phosphorus cycling in the mid-bay sediments in the Chesapeake Bay. Environ. Sci. Technol. 2015, 49, 5887-5896. [CrossRef]

11. Li, W.; Joshi, S.R.; Hou, G.; Burdige, D.J.; Sparks, D.L.; Jaisi, D.P. Characterizing phosphorus speciation of Chesapeake Bay sediments using chemical extraction, ${ }^{31} \mathrm{P} \mathrm{NMR}$, and X-ray Absorption Fine Structure Spectroscopy. Environ. Sci. Technol. 2014, 49, 203-211. [CrossRef] [PubMed]

12. O'Connell, D.W.; Ansems, N.; Kukkadapu, R.K.; Jaisi, D.; Orihel, D.M.; Cade-Menun, B.J.; Hu, Y.; Wiklund, J.; Hall, R.I.; Chessell, H.; et al. Changes in sedimentary phosphorus burial following artificial eutrophication of Lake 227, Experimental Lakes Area, Ontario, Canada. J. Geophys. Res. Biogeosci. 2020. [CrossRef]

13. Thandrup, B. Bacterial manganese and iron reduction in aquatic sediments. In Advances in Microbiol Ecology; Kluwer Academic/Plenum Publishing: New York, NY, USA, 2000; Volume 16, pp. 41-84.

14. Giguet-Covex, C.; Poulenard, J.; Chalmin, E.; Arnaud, F.; Rivard, C.; Jenny, J.-P.; Dorioz, J.-M. XANES spectroscopy as a tool to trace phosphorus transformation during soil genesis and mountain ecosystem development from lake sediments. Geochim. Cosmochim. Acta 2013, 118, 129-147. [CrossRef]

15. Gu, C.; Dam, T.; Hart, S.C.; Turner, B.L.; Chadwick, O.A.; Berhe, A.A.; Hu, Y.; Zhu, M. Quantifying uncertainties in sequential chemical extraction of soil phosphorus using XANES spectroscopy. Environ. Sci. Technol. 2020, 54, 2257-2267. [CrossRef] 
16. Psenner, R.; Pucsko, R.; Sager, M. Fractionation of organic and inorganic phosphorus compounds in lake sediments: An attempt to characterize ecologically important fractions. Archiv. Fuer. Hydrobiol. 1984, 70, 111-155.

17. Paludan, C.; Jensen, H.S. Sequential extraction of phosphorus in freshwater wetland and lake sediment: Significance of humic acids. Wetlands 1995, 15, 365-373. [CrossRef]

18. Reitzel, K. Separation of aluminum bound phosphate from iron bound phosphate in freshwater sediments by a sequential extraction procedure. In Phosphate in Sediments; Serano, L., Golterman, H.L., Eds.; Backhuys Publishers: Leiden, The Netherlands, 2005; pp. 109-117.

19. Ruttenberg, K.C. Development of a sequential extraction method for different forms of phosphorus in 889 marine sediments. Limnol. Oceanogr. 1992, 37, 1460-1482. [CrossRef]

20. Baldwin, D.S. The phosphorus composition of a diverse series of Australian sediments. Hydrobiologia 1996, 335, 63-73. [CrossRef]

21. Hesterberg, D.; Zhou, W.Q.; Hutchison, K.J.; Beauchemin, S.; Sayers, D.E. XAFS study of adsorbed and mineral forms of phosphate. J. Synchrotron Radiat. 1999, 6, 636-638. [CrossRef]

22. Prietzel, J.; Dümig, A.; Wu, Y.; Zhou, J.; Klysubun, W. Synchrotron-based P K -edge XANES spectroscopy reveals rapid changes of phosphorus speciation in the topsoil of two glacier foreland chronosequences. Geochim. Cosmochim. Acta 2013, 108, 154-171. [CrossRef]

23. Cade-Menun, B.J. Characterizing phosphorus in environmental and agricultural samples by ${ }^{31} \mathrm{P}$ nuclear magnetic resonance spectroscopy. Talanta 2005, 66, 359-371. [CrossRef]

24. Cade-Menun, B.J. Improved peak identification in P-31-NMR spectra of environmental samples with a standardized method and peak library. Geoderma 2015, 257, 102-114. [CrossRef]

25. Ajiboye, B.; Akinremi, O.O.; Hu, Y.F.; Flaten, D.N. Phosphorus speciation of sequential extracts of organic amendments using NMR and XANES spectroscopies. J. Environ. Qual. 2007, 36, 1563-1576. [CrossRef] [PubMed]

26. Liu, J.; Hu, Y.; Yang, J.; Abdi, D.; Cade-Menun, B.J. Investigation of soil legacy phosphorus transformation in long- term agricultural fields using sequential fractionation, P K-edge XANES and solution P-NMR spectroscopy. Environ. Sci. Technol. 2015, 49, 168-176. [CrossRef] [PubMed]

27. Kar, G.; Hundal, L.S.; Schoenau, J.J.; Peak, D. Direct chemical speciation of P in sequential chemical extraction residues using P Kedge X-ray absorption near-edge structure spectroscopy. Soil Sci. 2011, 176, 589-595. [CrossRef]

28. Cooper, R.J.; Rawlins, B.G.; Kreuger, T.; Lézé, B.; Hiscock, K.M.; Pedentchouk, N. Contrasting controls on the phosphorus concentration of suspended particulate matter under base flow and storm event conditions in agricultural headwater streams. Sci. Total Environ. 2015, 533, 49-59. [CrossRef] [PubMed]

29. Rawlins, B.G. Controls on the phosphorus content of fine stream bed sediment in agricultural headwater catchments at the landscape scale. Agric. Ecosyst. Environ. 2011, 144, 352-363. [CrossRef]

30. Environment Protection Agency. Water Quality in 2017: An Indicators Report; Environment Protection Agency of Ireland: Dublin, Ireland, 2018.

31. Phillips, J.M.; Russell, M.A.; Walling, D.E. Time-integrated sampling of suspended sediment: A simple methodology for small catchments. Hydrol. Process. 2000, 14, 2589-2602. [CrossRef]

32. Hupfer, M.; Zak, D.; Rossberg, R.; Herzog, C.; Pothig, R. Evaluation of a well-established sequential phosphorus fractionation technique for use in calcite-rich lake sediments: Identification and prevention of artifacts due to apatite formation. Limnol. Oceanogr. Methods 2009, 7, 399-410. [CrossRef]

33. Xiao, Q.; Maclennan, A.; Hu, Y.; Hackett, M.; Leinweber, P.; Sham, T.-K. Medium-energy microprobe station at the SXRMB of the CLS. J. Synchrotron Rad. 2017, 24, 333-337. [CrossRef]

34. Fay, D.; Kramers, G.; Zhang, C.; McGrath, D.; Grennan, E. Soils Geochemical Atlas of Ireland; Teagasc and the Environmental Protection Agency: Dublin, Ireland, 2007; ISBN 1-84170-489-1.

35. Wang, J.Y.; Pant, H.K. Enzymatic hydrolysis of organic phosphorus in river bed sediments. Ecol. Eng. 2010, 36, 963-968. [CrossRef]

36. Zhang, W.; Tang, W.; Zhang, H.; Jianlin, B.; Jin, X.; Li, J.; Shan, B. Characterization of biogenic phosphorus in sediments from the multi-polluted Haihe River, China, using phosphorus fractionation and ${ }^{31} \mathrm{P}-\mathrm{NMR}$. Ecol. Eng. 2014, 71, 520-526. [CrossRef]

37. Fay, D.; Kramers, G.; Zhang, C. Soil Geochemical Atlas of Ireland; SAFER/EPA: Johnstown Castle, Ireland; Available online: http://erc.epa.ie/safer/iso19115/display?isoID=105 (accessed on 31 July 2020). 
38. Van der Grift, B.; Behrends, T.; Osté, L.A.; Schot, P.P.; Wassen, M.J.; Griffioen, J. Fe hydroxyphosphate precipitation and $\mathrm{Fe}(\mathrm{II})$ oxidation kinetics upon aeration of $\mathrm{Fe}(\mathrm{II})$ and phosphate-containing synthetic and natural solutions. Cosmochim. Acta Geochim. 2016, 186, 71-90. [CrossRef]

39. Smolders, E.; Baetens, E.; Verbeeck, M.; Nawara, S.; Diels, J.; Verdievel, M.; Peeters, B.; De Cooman, W.; Baken, $\mathrm{S}$. Internal loading and redox cycling of sediment iron explain reactive phosphorus concentrations in lowland rivers. Environ. Sci. Technol. 2017, 51, 2584-2592. [CrossRef] [PubMed]

40. Mockler, E.M.; Deakin, J.; Archbold, M.; Gill, L.; Daly, D.; Bruen, M. Sources of nitrogen and phosphorus emissions to Irish rivers and coastal waters: Estimates from a nutrient load apportionment framework. Sci. Total Environ. 2017, 601-602, 326-339. [CrossRef]

41. Joseph, M.M.; Kumar, C.S.R.; Renjith, K.R.; Kumar, T.R.G.; Chandramohanakumar, N. Phosphorus fractions in the surface sediments of three mangrove systems of southwest coast of India. Environ. Earth Sci. 2011, 62, 1209-1218. [CrossRef]

42. Liu, J.; Sui, P.; Cade-Menun, B.J.; Hu, Y.; Yang, J.; Huang, S.; Ma, Y. Molecular-level understanding of phosphorus transformation with long-term phosphorus addition and depletion in an alkaline soil. Geoderma 2019, 353, 116-124. [CrossRef]

43. Zimmer, D.; Kruse, J.; Siebers, N.; Panten, K.; Oelschlager, C.; Warkentin, M.; Hu, Y.; Zuin, L.; Leinweber, P. Bone char vs S-enriched bone char: Multi-method characterization of bone chars and their transformation in soil. Sci. Total Environ. 2018, 643, 145-156. [CrossRef]

44. Baumann, K.; Siebers, M.; Kruse, J.; Eckhardt, K.-U.; Hu, Y.; Michalik, D.; Siebers, N.; Kar, G.; Karsten, U.; Leinweber, P. Biological soil crusts as key player in biogeochemical P cycling during pedogenesis of sandy substrate. Geoderma 2019, 338, 145-158. [CrossRef]

45. Wang, X.; Hu, Y.; Tang, Y.; Yang, P.; Feng, X.; Xu, W.; Zhu, M. Phosphate and phytate adsorption and precipitation on ferrihydrite surfaces. Environ. Sci. Nano 2017, 4, 2193-2204. [CrossRef]

(C) 2020 by the authors. Licensee MDPI, Basel, Switzerland. This article is an open access article distributed under the terms and conditions of the Creative Commons Attribution (CC BY) license (http://creativecommons.org/licenses/by/4.0/). 